\title{
REFUGIADOS NO SISTEMA INTERNACIONAL: UM LIMBO DE PROTEÇÃO
}

\author{
Aryadne Bittencourt Waldely ${ }^{1}$
}

Resumo: O presente artigo objetiva identificar as falhas e as lacunas do sistema internacional dos Direitos Humanos acerca da proteção aos refugiados. Foi realizado um estudo interdisciplinar entre Direito e Relações Internacionais como tentativa de analisar como os refugiados, um grupo em situação de extrema vulnerabilidade, são acolhidos, no direito internacional, em termos de proteção e promoção de direitos. A metodologia utilizada baseia-se em pesquisa analítica e qualitativa acerca de produções acadêmicas, documentos internacionais e relatórios do Alto Comissariado das Nações Unidas para Refugiados, tornando possível constatar que os refugiados encontram-se em limbo de direitos devido ao fato de fugirem à regra do sistema internacional fundado em Estados-Nação. O que há são tentativas de minimizar a perda da dignidade humana dos refugiados sem, contudo, suprir adequadamente sua demanda eminente.

Palavras-Chave: Refugiados. Sistema Internacional de Proteção. Direitos Humanos. Direito Internacional dos Refugiados. ACNUR.

\begin{abstract}
This article aims to identify gaps and shortcomings of the international system of human rights regarding the protection of refugees. An interdisciplinary study of Law and International Relations was conducted in an attempt to analyze how the refugees, as precarious group, is incorporated in international law, in terms of protection and promotion of rights. The methodology is based on qualitative and analytical research about academic productions, international documents
\end{abstract}

1 Mestranda na linha de Direitos Humanos, Sociedade e Arte do PPGD da Universidade Federal do Rio de Janeiro, pesquisadora do Laboratório de Direitos Humanos da Universidade Federal do Rio de Janeiro, assistente de elegibilidade da Cáritas Arquidiocesana do Rio de Janeiro. E-mail: aryadnebittencourt@gmail.com. 
and reports of the United Nations High Commissioner for Refugees, making it possible to verify that the refugees are in limbo of rights due to the fact that they are not included in the rule of international system grounded on nation-states. There are attempts to minimize the loss of human dignity of refugees, but they are not adequately able to respond to his lofty demand.

Keywords: Refugees. International System of Protection. Human Rights. International Refugee Law. UNHCR.

\section{INTRODUÇÃO}

O fluxo de refugiados é considerado um problema global crescente. Muito embora não seja um problema recente, existindo desde tempos remotos devido a guerra, violações massivas de direitos humanos, golpes militares, entre outros (LOESCHER, 1993, p. 3), em 2013, foram contabilizadas mais de 50 milhões de pessoas que passaram por deslocamento forçado, o maior número desde a Segunda Guerra Mundial (UNHCR, 2014). Mediante isso, a atenção da comunidade internacional, sobretudo de Estados e agências humanitárias, vem crescendo para tentar lidar com a demanda dos refugiados.

O fim da Guerra Fria ensejou um cenário de maior preocupação com o tema, já que as barreiras entre o hemisférios norte e o sul foram significativamente diminuídas, proporcionando um aumento no número de solicitantes de refúgio nos países industrializados ocidentais. A partir de então, os atores internacionais que atendem às demandas humanitárias tiveram que se adaptar aos diferentes cenários que surgiam. As demandas humanitárias eram basicamente as mesmas: fome, desnutrição, situação de violência, doenças, violação massiva de direitos humanos. Todavia, as emergências humanitárias do pós-Guerra Fria estão em sua grande medida inseridas num contexto de maior diversidade de atores e de diferentes possibilidades de atuação. Com isso, houve maior envolvimento na questão por parte de "agências humanitárias, organizações de direitos humanos, forças militares multinacionais, negociadores de paz, investigadores de crimes de guerra, jornalistas e diversos outros atores internacionais" (ACNUR, 2000, p. 1).

Observa-se, então, que as mudanças ocorridas com o fim da Guerra Fria devem-se mais ao aumento da diversidade e do número de atores envolvidos na resposta humanitária e menos aos dilemas humanitários em si. As agências humanitárias, por exemplo, estão muito mais presentes em situações de emergência no pós-Guerra Fria do que antes (TERRY, 2002, p. 5-13). Contudo, esse interesse pelo tema não é suficiente 
para resolvê-lo, pois não há solução permanente e satisfatória para todas as demandas humanitárias dos refugiados (LOESCHER, 1993, p. 4).

Agências humanitárias internacionais, como Médicos Sem Fronteiras e Comitê Internacional da Cruz Vermelha, por exemplo, se esforçam para lidar com a questão dos refugiados, porém se deparam com grandes dificuldades que estão relacionadas à própria condição do refugiado. Ou seja, o refugiado é fruto de alicerces falhos que sustentam a arquitetura do sistema internacional e que não garantem a proteção humana. Isto porque, considerando um tipo ideal de sistema de Estados, democráticos e garantidores de direitos, os refugiados seriam uma espécie de anomalia, já que não estariam previstos dentro da normalidade de tal estrutura.

Giorgio Agamben (2000) disserta sobre os limites impostos aos direitos humanos na relação entre Estado e indivíduo, criticando a relação que parece ser indissociável entre garantia de direitos humanos, por um lado, e os desígnios do Estado-nação moderno, por outro. Desse modo, os tratados internacionais de direitos humanos, como a Convenção das Nações Unidas para o Estatuto dos Refugiados de 1951, conhecida como Convenção de 1951 ou Convenção de Genebra, são, de modo geral, bem aceitos pelos Estados. A despeito disso, a promoção de direitos nem sempre é observada por eles, sobretudo quando se trata de refugiados (RIEFF, 2002, p. 15). Assim, pode-se inferir que quando o aparato estatal não se faz presente, os indivíduos, sobretudo os refugiados, não verificam a execução de seus direitos (ARENDT, 1989).

Hannah Arendt (1989), no livro Origens do Totalitarismo, discorre sobre as implicações do distanciamento entre o indivíduo e o Estado-nação, chamando a atenção para a ausência de garantia de direitos para grupos como refugiados e apátridas. A íntima relação entre Estado, cidadania e Direitos Humanos, afirmada no contexto das declarações de direito assinadas pela maioria dos Estados, evidencia quão seletiva é a possibilidade de se exercer direitos, considerando que tais grupos apartam-se do caráter de cidadão. Dessa forma, a autora assevera que o "direito a ter direitos" não contempla, na prática, todos os indivíduos.

Nesse ínterim, o jurista Antonio Augusto Cançado Trindade (1997) demonstra que já há arcabouço jurídico internacional suficiente para proteger os direitos humanos estabelecidos. $\mathrm{O}$ que nos resta é saber como implementá-los. Assim sendo, muito embora o propósito de proteção aos refugiados seja respaldado pelo Direito Internacional Humanitário e dos Refugiados, especificamente, o enforcement dessa normativa internacional não é bem observado (TERRY, 2002).

Diante desse cenário, este artigo propõe-se a apresentar a inadequação 
do refugiado no sistema internacional formado por Estados soberanos e a consequente peculiaridade dos seus direitos decorrentes de tal regime de proteção. A problemática que motiva este estudo refere-se a uma necessidade natural de proteção e promoção de direitos dos refugiados em detrimento de um sistema de proteção internacional limitado às predisposições dos Estados. Nesse sentido, o problema de pesquisa constitui em analisar como os refugiados se inserem no sistema internacional de proteção.

Dessa forma, o objetivo geral do artigo é identificar as falhas e as lacunas do sistema internacional dos Direitos Humanos acerca da proteção aos refugiados. Os objetivos específicos estão esquematizados em três seções, além desta introdução e das considerações finais. Primeiramente, busca-se compreender a dificuldade de inserção dos refugiados no Sistema Internacional de Proteção da Pessoa Humana. Em seguida, o objetivo é investigar a proposta de proteção internacional para os refugiados dentro da lógica de Estados-Nação. Posteriormente, visa-se descrever brevemente o papel do Alto Comissariado das Nações Unidas para o Refugiados na proteção das pessoas que sofreram deslocamento forçado (ACNUR).

Metodologicamente, este estudo baseia-se em pesquisa analítica e qualitativa realizada a partir da apreciação de literatura específica sobre Direitos Humanos, refugiados, humanitarismo e sistema internacional, além de documentos internacionais tangentes ao tema de proteção a refugiados, com destaque para Convenção de 1951, e relatórios do ACNUR. Para tanto, o artigo traça relações entre Direito Internacional dos Direitos Humanos, filosofia politica e relações internacionais a fim de analisar a fragilidade do sistema internacional de proteção.

\section{O LIMBO PARA OS REFUGIADOS NO SISTEMA INTERNACIONAL DE PROTEÇÃO DA PESSOA HUMANA}

Como já mencionado, o sistema internacional de proteção dos direitos humanos está baseado na garantia de direitos por parte dos Estados. Todavia, fenômenos como a migração internacional trazem à tona os limites existentes dentro do sistema internacional de direitos humanos. Pois, o fato de cruzar a fronteira implica uma dificuldade crescente em exercer tais direitos ou até mesmo de conclamar seu reconhecimento enquanto pessoa que possui direitos. No caso da migração forçada, os refugiados emigram porque o seu Estado de origem foi incapaz de ou negligente em garantir sua segurança e seus direitos fundamentais, impondo-lhes a obrigação de sair do país em busca de proteção da comunidade internacional (BETTS; LOESCHER, 
2011). Todavia, tal comunidade não tem obtido sucesso em garantir os direitos dos refugiados devido aos limites apresentados pela ordem internacional em que vivemos, baseada em Estados-Nação ${ }^{2}$. O princípio de Estado soberano é basilar nesse sistema e restringe as relações políticas internacionais, de maneira que pessoas, bens e relações de modo geral sejam concebidos somente de acordo com a lógica estatal.

Arendt, por exemplo, vivenciou o dilema dos direitos humanos atrelados à lógica da soberania e dedicou grande parte de sua vida a refletir e expressar seus pensamentos acerca dessa limitação. O contexto vivido pela autora é de uma Europa da primeira metade do século XX governada por diversos regimes totalitários que perpetraram genocídio e geraram significante fluxo de refugiados e apátridas. Suas colocações acerca dessa situação, corroboradas por Agamben, vão no sentido de repensar a maneira como o "direito a ter direitos" se insere na política internacional. Esses e outros autores dissertam sobre os limites impostos aos direitos humanos na relação entre Estado e indivíduo.
Nesse sentido, Arendt (1989) entrevê um paradoxo nesta relação entre Estado e cidadão mediante a situação de grupos vulneráveis como os refugiados, casos em que o embasamento dos direitos humanos realizado a partir da relação direta com a ideia de ser humano não é factível. Pois, os refugiados por muitas vezes parecem perder características de "ser humano" e, então, perdem igualmente os seus direitos. A situação de refúgio coloca as pessoas num limbo de direitos. Isto é, os refugiados são tratados como pessoas mais em termos de potencial e princípio do que de viabilidade de exercer direitos. Sendo assim, os refugiados são vistos como seres humanos em suspenso, pois seus direitos humanos não foram ideologicamente perdidos nem recebidos, mas é como se estivessem sido suspensos.

Dessa forma, a afirmação dos direitos humanos foi concebida para funcionar dentro da concepção da relação entre o cidadão e seu Estado-nação, de modo que os refugiados se deparem muitas vezes com a negação dos direitos. Não há lugar para os refugiados

2 Estado-nação é um conceito utilizado para designar o modelo de Estado em ascensão a partir do século 18. Qual seja, a existência de um território no qual os cidadãos identificam-se com uma mesma nação, o que inclui identidade cultural, etnia e idioma. De acordo com a Organização das Nações Unidas para a Educação, a Ciência e a Cultura. (UNESCO), The nation-state is an area where the cultural boundaries match up with the political boundaries. The ideal of 'nation-state' is that the state incorporates people of a single ethnic stock and cultural traditions. Disponível em: $<$ http://www.unesco.org/new/ en/social-and-human-sciences/themes/international-migration/glossary/nation-state/>. 
no mundo de entes soberanos. Agamben (2000, p. 128) esclarece essa questão, afirmando que:

Se os refugiados [...] representam, no ordenamento do Estado-nação moderno, um elemento tão inquietante, é antes de tudo porque, rompendo a continuidade entre homem e cidadão, entre nascimento e nacionalidade, eles põem em crise a ficção originária da soberania moderna. Exibindo à luz o resíduo entre nascimento e nação, o refugiado faz surgir por um átimo na cena política aquela vida nua que constitui seu secreto pressuposto. Neste sentido, ele é [...], a sua primeira e única aparição real fora da máscara do cidadão que constantemente o cobre. Mas, justamente por isso, a sua figura é tão difícil de definir politicamente.

Esta necessidade de garantir os direitos humanos por meio dos Estados, gerada pelo modelo de Estado-nação vigente no sistema internacional, implica diversos problemas. De início, pode-se afirmar que o zelo do Estado para assegurar os direitos humanos fica diretamente dependente da condição de nacionalidade e de cidadania. Então, se um indivíduo perde a sua condição de cidadão do seu Estado de origem, a garantia dos seus direitos humanos por tal Estado sucumbe. Portanto, a atual configuração política do sistema internacional de proteção centraliza o papel garantidor de direitos no Estado, de modo que o desmantelamento do aparato estatal para um indivíduo tende a significar a perda de seus direitos, pondo em cheque a universalidade dos direitos humanos.

Além disso, o Estado é muitas vezes o próprio violador de direitos. Não se esgotam exemplos a serem citados de casos em que o Estado não cumpriu com seu dever de proteger seus cidadãos. Esse comportamento é típico de governos ditatoriais que existiram, por exemplo, em Camboja, na Armênia, em Ruanda, na Somália, e muitos outros que ainda existem em grande número na atualidade. Ou seja, não só não há garantia de direitos sem a presença de um Estado, como tampouco a execução dos direitos humanos é sempre assegurada na relação Estado-cidadãos. Pelo contrário, observa-se que os Estados protegem os direitos dos cidadãos quando lhe é conveniente fazer, não pelo dever de promover direitos humanos fundamentais.

Ora, se os direitos humanos têm por objetivo estabelecer uma base comum de dignidade entre os seres humanos, permitindo que eles tenham direitos mínimos, como ocorre a construção dos mesmos dada a condição diferente dos seres humanos? Uma conclusão inevitável e indesejada que surge é a de que alguns seres humanos têm possibilidades diferentes de exercer direitos em relação a outras pessoas, ou até mesmo que, na prática, uns têm mais direitos do que outros. Esse cenário nos leva a pensar na inaplicabilidade dos direitos humanos defendidos em teoria 
devido às condições impostas por políticas nacionais e internacionais. Com isso, vê-se a necessidade de repensar a relação da condição de humano nos aspectos mais abrangentes relacionados ao "direito a ter direitos".

Vale retomar aqui as reflexões desenvolvidas por Agamben acerca da vida nua. O autor elabora uma noção de "vida natural desprotegida" de acordo com a qual os indivíduos não teriam "direitos" humanos a priori, no sentido de eles serem quase que uma tabula rasa, que passa a ser preenchida somente quando inserida na lógica político-jurídica do Estado-nação. Ou seja, o indivíduo que se encontra fora de tal ordem é constituído por uma vida desprotegida, pois não tem a "roupa protetora" do aparato estatal.

Nesse sentido, falar em soberania do povo pode ser uma tarefa bastante árdua. Uma vez que os direitos humanos só são entendidos, na prática, dentro da lógica do Estado-nação, não é óbvio entender a suposta autonomia dos indivíduos como soberana, pois o que prevalece nessa ordem estatal é a soberania do Estado. Contudo, e os direitos humanos? Estariam eles completamente subjugados à vontade política dos Estados? Para Arendt e Agamben, a resposta tende ao "sim". Destarte, Arendt considera que "a própria expressão direitos humanos tornou-se uma prova de idealismo fútil ou de tonta e leviana hipocrisia" (Arendt, 1989, p. 302). Diante disso, é justo repensar o "direito a ter direitos", que não deve ser limitado à ação política, mas inserido na possibilidade de aumentar o seu potencial num momento em que o sistema de Estado-nação claramente não oferece "boa vida" para todos os indivíduos.

Considerando essa problemática de proteção aos refugiados, é inevitável observar que o sistema internacional de Estados não está preparado para atender às demandas desse grupo. Emma Haddad (2008, p. 3), pesquisadora do fenômeno do deslocamento forçado, ${ }^{3}$ afirma que os refugiados são como indicadores humanos da falência da sociedade internacional. De acordo com a autora, o refúgio encontra-se justamente no interregno entre o internacional e $o$ doméstico. Ao mesmo tempo em que os refugiados ficam sem saber exatamente a quem recorrer, os Estados não se sentem naturalmente obrigados a lhes assistir. A princípio, todo indivíduo "pertence" a um

3 Deslocamento forçado é definido pelo Banco Mundial como a situação na qual as pessoas são forçadas a sair ou fugir de suas casas devido a conflito, violência, perseguição e violações de direitos humanos, podendo ela ser de duas categorias: refugiados ou deslocados internos. Conferir: WORLD BANK, THE. Forced Displacement, 2013. Disponível em: <http:/web.worldbank.org/WBSITE/EXTERNAL/TOPICS/EXTSOCIADEVELOPMENT/0,,contentMDK:22463823 pagePK:148956 piPK:216618 theSitePK:244363,00.html>. Acesso em: 20 jun. 2013. 
Estado. Todavia, quando essa situação não se verifica, ele torna-se um indivíduo internacional. Com isso, entende-se que o refúgio é, contraditoriamente, um fenômeno decorrente do sistema internacional de Estados. Não haveria refugiados sem a existência de tal sistema.

Haddad (2008, p. 5-8) também explica que, muito embora a ocorrência do refúgio sempre tenha ocorrido desde a concretização do sistema internacional de Estados modernos, o fluxo contemporâneo de refugiados apresenta certa peculiaridade 4 . Com o fim da Guerra Fria, a migração de larga escala frequentemente transforma-se em imigração permanente, fazendo com que haja cada vez menos refugiados que consigam repatriar-se. Esse resultado não podia ser diferente, tendo em vista que a construção de fronteiras políticas separa os Estados e cria diferenças claras entre insiders e outsiders. Enquanto houver essa divisão dicotômica, haverá refugiados. Por conseguinte, o imperfeito sistema de Estados soberanos é um dos grandes fatores responsáveis pela criação de refugiados.

Dessa forma, o regime internacional de proteção aos refugiados deve responder às mudanças das emergências complexas ${ }^{5}$ e do deslocamento humano (HYNDMAN, 2000). Só assim os refugiados podem vislumbrar uma possibilidade mais concreta de viver com plena vigência de seus direitos. Caso contrário, a sociedade internacional falha na sua obrigação para com o refugiado.

Os Estados não podem ignorar a existência de refugiados. Além dos refugiados serem pessoas com (potencial para) dignidade humana, a causa dos diversos e numerosos fluxos de refugiados não pode ser explicada sem considerar a estrutura em que os Estados estão organizados. Há uma relação mutuamente constitutiva entre o conceito de refugiado e de sociedade internacional. O refúgio tornou-se uma característica inevitável do cenário internacional com a consolidação do sistema moderno de Estados-nação (HADDAD, 2008, p. 1-8).

4 Haddad, em seu livro The Refugee in International Society: between sovereigns, considera três fases para analisar o refúgio numa perspectiva histórica do século 20 : entre-guerras; durante a Guerra Fria; e pós a Guerra Fria.

5 A definição utilizada pelo Comitê Permanente Interagências para Assuntos Humanitários da ONU para "emergências complexas" é "a humanitarian crisis in a country, region or society where there is total or considerable breakdown of authority resulting from internal or external conflict and which requires an international response that goes beyond the mandate or capacity of any single agency and/ or the ongoing United Nations country program." Conferir: OFFICE FOR THE COORDINATION OF HUMANITARIAN AFFAIRS. OCHA Orientation Handbook on Complex Emergencies, 1999. Disponível em: <http://reliefweb. int/sites/reliefweb.int/files/resources/3D153DA3049B322AC1256C30002A9C24ocha_orientation_handbook_on_.html >. Acesso em: 20 jun. 2013. 
Por conseguinte, vale ressaltar que a problemática do refúgio não se resume a questões meramente humanitárias, mas envolve também (ou sobretudo) relações de poder político. As organizações não governamentais geralmente usam o discurso do humanitarismo porque faz parte de seu mandato na condição de entidade do terceiro setor. Contudo, esse argumento é diversas vezes utilizado inadequadamente por governos que tentam esconder as motivações políticas de suas decisões, sendo que cabe resposta apolítica para migração forçada (HYNDMAN, 2000).

Tendo em vista as relações políticas da modernidade, não é surpresa que haja inúmeras pessoas com seus direitos políticos e sociais desrespeitados dentro do seu Estado de origem. Assim, essas pessoas se veem obrigadas a saírem desse Estado por questões de sobrevivência. Não é por acaso que o refúgio seja uma das principais expressões da dificuldade do sistema internacional de proteção em garantir direitos. Isto quer dizer que os refugiados não migram porque simplesmente almejam ter uma experiência no exterior ou porque buscam melhores condições econômicas. Estes seriam considerados migrantes regulares. Os refugiados, porém, saem do país de origem porque não têm a possibilidade de sobreviverem dignamente nesse lugar. Para alguém que se torna refugiado, o que era até então seu lar deixa de ser um abrigo seguro.
Muito embora os refugiados busquem escapar de situações perigosas ou desumanas em seu país de origem, não necessariamente eles encontram vida digna no país receptor. Esse labirinto de truculência deve-se em grande medida ao fato de que os fluxos de refugiados são fruto de relações internacionais altamente politizadas. Mais que isso, os governos não sabem lidar efetivamente com a questão do refúgio, que está além da capacidade deles de fazerem valer os direitos a todos (HYNDMAN, 2000, p. 2-3). Ademais, o fracasso das medidas tomadas é também decorrente da natureza política e internacional do refugiado. Pois o refúgio é um fenômeno complexo e relacionado a uma multiplicidade de atores, dependendo, portanto, de uma resposta de igual complexidade. Diante desse cenário de extrema precariedade dos refugiados, é indispensável que haja uma forma alternativa de proteção que não seja estatal.

\section{A TENTATIVA \\ DE PROTEÇÃO \\ INTERNACIONAL \\ PARA OS REFUGIADOS}

Considerando que a perspectiva crítica deste trabalho diz respeito à dificuldade de promoção dos direitos dos refugiados no desenho internacional, faz-se fundamental discutir a proteção 
internacional prevista para os refugiados. De acordo com Cançado Trindade (2007), a proteção internacional da pessoa humana está baseada em três pilares: Direito Internacional dos Direitos Humanos (DIDH); Direito Internacional Humanitário (DIH); e Direito Internacional dos Refugiados (DIR). O DIDH versa sobre a proteção de direitos fundamentais da pessoa humana de modo geral. Já o DIH tem a especificidade de atender a alguns cuidados peculiares a situações de conflito. Por fim, o DIR, como o próprio nome sugere, trata das demandas dos refugiados. Estas vertentes não são excludentes; pelo contrário, são complementares, na medida em que elas atendem a situações diversas em prol de direitos fundamentais. Respeitando o propósito de indivisibilidade dos direitos humanos, há uma tendência de que esses três pilares convirjam em detrimento de um pensamento anterior que concebia três vertentes dos direitos humanos. Tal convergência fez-se imperativa para promover uma proteção mais ampla e integral à pessoa humana.

No caso dos refugiados, viu-se a necessidade de assegurar seus direitos de forma específica devido à peculiaridade na qual eles se encontram no regime internacional. A situação dessas pessoas sem proteção nacional implica resultados tão desastrosos decorrentes de fluxos intensos de refúgio que foi preciso criar mecanismos internacionais além da legislação interna do Estado para protegê-las. Como a Declaração Universal dos Direitos Humanos não tem caráter obrigatório de vinculação, seria imprescindível elaborar um instrumento jurídico que pudesse comprometer os Estados para com os refugiados (CUNHA; ALMEIDA, 2008, p. 438). Numa cartilha informativa do Alto Comissariado das Nações Unidas para Refugiados - ACNUR - (ACNUR, 2011), a pergunta "Por que os refugiados precisam de proteção?" é respondida da seguinte forma:

Estado são responsáveis pela proteção dos direitos humanos fundamentais dos seus cidadãos. Quando eles são incapazes ou não querem fazê-lo [...] os indivíduos podem sofrer tão graves violações de seus direitos humanos que eles têm que deixar suas casas, suas famílias e suas comunidades para encontrar refúgio em outro país ${ }^{6}$.

A partir dessa motivação, foram celebrados acordos internacionais com o objetivo de proteger aqueles indivíduos que se encontram fora da proteção do Estado, ou seja, refugiados e apátridas.

6 Tradução livre de "States are responsible for protecting the fundamental human rights of their citizens. When they are unable or unwilling to do so [...] individuals may suffer such serious violations of their human rights that they have to leave their homes, their families and their communities to find sanctuary in another country", no original em inglês. 
Nesse contexto, tais declarações de direito apresentam uma função histórica significante, pois possibilitaram a institucionalização do vínculo entre direitos do homem e a soberania moderna (AGAMBEN, 2000, p.125-127). Isto porque os tratados internacionais de direitos humanos inevitavelmente refletem a realidade política presente nas relações sociais, econômicas e diplomáticas.

Os principais documentos internacionais para proteção dos refugiados são a Convenção das Nações Unidas sobre o Estatuto dos Refugiados (CONHECIDA como a Convenção de 1951) e o Protocolo Relativo ao Estatuto dos Refugiados (normalmente nominado como Protocolo de 1967). A Convenção de 1951, que entrou em vigor em 1954, é tradicionalmente a base para assegurar os direitos humanos desses indivíduos, sendo um marco no DIR. Muito embora tenham havido iniciativas anteriores a favor dos refugiados (como Convenção Relativa ao Estatuto dos Refugiados Provenientes da Alemanha, de 1938, e Constituição da Organização Internacional para os Refugiados, de 1948), a
Convenção de 1951 consolidou e codificou os direitos dos refugiados em nível internacional, estabelecendo padrões básicos para o tratamento de refugiados. Atualmente, a definição de refugiado adotada pelo ACNUR (2011), baseada na Convenção de 1951, é:

Uma pessoa que está fora do seu país de nacionalidade ou de residência habitual; tem um fundado temor de perseguição por motivos de sua raça, religião, nacionalidade, pertencimento a um determinado grupo social ou opinião política; e não possa ou não queira se valer da proteção desse país, ou voltar lá, por medo de perseguição ${ }^{7}$.

A noção refugiado nem sempre foi entendida dessa forma. No momento anterior à Paz de Vestefália de $1648,{ }^{8}$ os refugiados eram basicamente aquelas pessoas que estavam saindo de uma situação de conflito ou de perseguição política ou religiosa (AGAMBEN, 2000, p. 2). Portanto, a definição mais precisa trazida pela Convenção de 1951 pode parecer trivial, mas foi fundamental para que um avanço nas políticas internacionais tenha sido dado. Além de ter

7 Tradução livre de "A person who is outside his or her country of nationality or habitual residence; has a well-founded fear of being persecuted because of his or her race, religion, nationality, membership of a particular social group or political opinion; and is unable or unwilling to avail him or herself of the protection of that country, or to return there, for fear of persecution" do original em inglês.

8 A chamada Paz de Vestefália foi uma série de tratados internacionais celebrados na Europa mediante o fim da Guerra dos Trinta Anos no ano de 1648 e é geralmente considerada o ponto de partida do sistema internacional moderno enquanto comunidade de Estados soberanos. 
definido o termo "refugiado", uma das principais contribuições da Convenção de 1951 foi trazer o princípio de non-refoulement (não-devolução, em francês). De acordo com esse princípio, "nenhum país deve expulsar ou "devolver" (refouler) um refugiado, contra a vontade do mesmo, em quaisquer ocasiões, para um território onde ele ou ela sofra perseguição" (ACNUR, 2013b).

Nesse sentido, o non-refoulement determina que os refugiados não poderão ser enviados para um país onde a sua vida ou a sua liberdade possam estar em perigo, por motivos de raça, religião, nacionalidade, pertencimento a um determinado grupo social ou político, ou ainda quando haja razões fundamentadas para crer que possa haver eventual tratamento cruel, desumano ou degradante. O embasamento jurídico para essa afirmação foram o Artigo 33 da Convenção sobre o Estatuto dos Refugiados de 1951; o Artigo 3 da Convenção contra a Tortura e Outros Tratamentos ou Penas Cruéis, Desumanos ou Degradantes de 1984; e o Artigo 22 da Convenção sobre os Direitos da Criança de 1989.

Contudo, apesar das qualidades, a Convenção de 1951 foi escrita num contexto histórico específico do pós-Segunda Guerra Mundial e a definição de "refugiado" que consta nela é limitada geográfica e temporalmente a tal conjuntura. Em resposta a essa limitação, o Protocolo de 1967 teve o importante papel de eliminar tais restrições da definição do termo "refugiado", expandindo o escopo do mandato do ACNUR e, então, de sua proteção. Apesar de o Protocolo estar relacionado com a Convenção, ele "é um instrumento independente cuja ratificação não é restrita aos Estados signatários da Convenção de 1951" (ACNUR, 2013b). Os Estados Unidos, por exemplo, são signatários somente do Protocolo, o que não os exime das responsabilidades para com os refugiados.

A Declaração de Cartagena sobre os Refugiado de 1984, proclamada na ocasião do "Colóquio sobre Proteção Internacional dos Refugiados na América Central, México e Panamá: Problemas Jurídicos e Humanitários", realizado em Cartagena das Índias, na Colômbia, também foi de grande importância para motivar políticas de proteção aos refugiados (PAM, 2004). Proclamada no contexto das ditaduras militares na América Latina, ela vislumbrou a ampliação do instituto do refúgio para situações de grave e generalizada violações de direitos humanos. Ademais, esta Declaração contribuiu para reiterar a relevância do princípio de non-refoulement, considerando-o uma pedra angular da proteção internacional dos refugiados. Além disso, esse documento prevê que o non-refoulement, enquanto princípio imperativo referente aos refugiados, deve ser reconhecido e respeitado no estado atual do direito internacional como um 
princípio de jus cogens, isto é, como uma norma peremptória geral do direito internacional que possui obrigatoriedade material e é inderrogável pela vontade das partes.

Não obstante, a Declaração de Cartagena também contribuiu para o desenvolvimento da definição do termo "refugiado". De acordo com a definição da Convenção de 1951, o "bem-fundado temor de perseguição" é um elemento fundamental para caracterizar o refugiado. Todavia, essa é uma característica subjetiva e, como tal, precisa ser avaliada de forma individual, não se adequando apropriadamente a situações de refúgio em massa. Mediante essa lacuna do Sistema Internacional de Direitos Humanos, a Declaração de Cartagena, adotada em novembro de 1984 por Estados americanos, pede que os países considerem a ampliação do termo "refugiado" para poder contemplar objetivamente a situação pela qual passavam os emigrantes da América Central no contexto dos conflitos do período. Deste modo, a Declaração de Cartagena solicita que:

A definição ou o conceito de refugiado recomendável para sua utilização na região é o que, além de conter os elementos da Convenção de 1951 e do Protocolo de 1967, considere também como refugiados as pessoas que tenham fugido dos seus países porque a sua vida, segurança ou liberdade tenham sido ameaçadas pela violência generalizada, a agressão estrangeira, os conflitos internos, a violação mas- siva dos direitos humanos ou outras circunstâncias que tenham perturbado gravemente a ordem pública.

Essa observação realizada pela Declaração de Cartagena reconhece que às vezes as pessoas saem do seu país de origem não porque foram ameaçadas de morte diretamente, mas devido à violência que toma conta do lugar, impossibilitando uma vida digna e segura. Com isso, há de se destacar um novo panorama para proteção aos refugiados. Se antigamente, em meados do século 19 , os refugiados eram analisados e estudados de forma mais individual e de acordo com sua situação de ameaça específica, hoje em dia o cenário é outro. Agamben (2000, p. 129) afirma que "os refugiados não representam mais casos individuais, mas, como acontece hoje mais e mais frequentemente, um fenômeno de massa". Atualmente, os refugiados de modo geral fazem parte de um fluxo cujo fato motivador foi ampla violência e/ou violação generalizada de direitos humanos. Essa nova concepção permitiu grandes avanços no continente americano, como demonstra o inciso III da Lei de Refúgio brasileira (Lei 9.474 de 1997) cujo teor abrange o estatuto do refúgio para aqueles que sejam submetidos a situações de grave e generalizada violação de direitos humanos.

Desde a década de 1950, o conceito de refugiado vem sendo ampliado para abranger um número maior de pessoas que demandam assistência e apresentam 
ausência de proteção estatal (ACNUR, 2000). Com isso, o regime internacional para refugiados passa a incluir os deslocados internos, que são pessoas com extrema precariedade cujo ímpeto migratório é oriundo da violência ou de abuso de direitos humanos, mas que não cruzam a fronteira do seu país, permanecendo em seu interior. Igualmente, as tentativas de proteção incentivadas sobretudo pelo ACNUR também expandem seu amparo aos asilados políticos, fenômeno ocorrido em massa na América Latina no contexto dos regimes ditatoriais dos anos 80. Essas diferentes manifestações de migração forçada estão em expansão e, com isso, desafiam a definição oficial da Convenção de 1951.

De todo modo, devido à natureza sui generis do refugiado, Haddad (2008) argumenta que há uma obrigação moral dos Estados diante da demanda humanitária gerada por esse grupo. $\mathrm{O}$ fortalecimento dessa obrigação moral do Estado é importante para aprimorar a inclusão dos refugiados no sistema internacional. Pois, contraditoriamente, os refugiados são ao mesmo tempo parte integrante e excluída do sistema internacional. Devido a esta e outras peculiaridades, os refugiados são uma figura excepcional no regime internacional de proteção e, logo, devem ser tratados como tal.

Nesse contexto, o humanitarismo, aqui entendido como a atuação por parte de agências humanitárias embasada num ideal de proteção humanitária e guiado pelo imperativo humanitário, torna-se uma questão fundamental. Atualmente, diversas agências humanitárias, não-governamentais e governamentais, internacionais, regionais e locais, se empenham para acolher as demandas do fluxo de migração forçada. As agências humanitárias não vislumbram, entretanto, acabar com todos os problemas e sofrimento dos refugiados, tampouco substituir os Estados em suas funções. Por meio da ajuda humanitária, elas buscam trazer um pouco de proteção humana a eles. Mesmo assim, vale lembrar que o "humanitarismo é por definição um emblema de fracasso, não de sucesso" (RIEFF, 2002, p. 19-22). A ação humanitária só existe porque os Estados falharam em cumprir com seus deveres estabelecidos internacionalmente. Com isso, os Estados "reinventam" a lógica de proteção humanitária e delegam a organizações multilaterais o papel de cuidar dos refugiados (HYNDMAN, 2000). A sociedade internacional realizou, então, um esforço em construir e fortalecer um órgão incumbido de cuidar dos refugiados. É sobre esse assunto que a subsequente seção versará.

\section{O PAPEL DO ACNUR}

O ACNUR é um dos principais órgãos das Nações Unidas. A agência conta com cerca de 8,6 mil pessoas em seu quadro de funcionários e um orçamento 
anual de US $\$ 3.59$ bilhões, estando presente em mais de 125 países para ajudar mais de 30 milhões de pessoas (ACNUR, 2013a). Tais números fazem notório o fato de que o ACNUR é uma entidade muito grande e com muito trabalho para fazer. No entanto, houve várias tentativas para lidar com os refugiados até chegarmos ao que hoje é o ACNUR.

Afora inciativas anteriores, é importante constatar que a I Guerra Mundial implicou uma reconfiguração nos Estados europeus, acarretando deslocamento em massa. Nesse contexto, fica evidente que a relação entre nacionalidade em virtude de nascimento e nação não é tão direta na realidade como se esperava que fosse de acordo com o sistema europeu de Estados-nação. Em resposta a esse grande número de refugiados russos, búlgaros, armênios, entre outros, os Estados criaram diversas normas nacionais e acordaram outros tratados internacionais como tentativa de se adaptarem à situação de intenso fluxo de refugiados (AGAMBEN, 2000, p. 128).

Foi criado, então, um regime de refugiados durante o período do entreguerras sob os auspícios da Liga das Nações entre 1921 e 1939. As iniciativas desse regime eram discricionárias, informais e ad hoc. A despeito disto, elas permitiram o desenvolvimento de uma estrutura internacional com regras que buscavam garantir a proteção dos refugiados. Uma contribuição muito significativa do período foi a institui- ção em 1922 dos "Passaportes Nansen” (Nansen Passports, em inglês). O passaporte Nansen fez parte do Alto Comissariado para Refugiados Russos instaurado em 1921 pela Sociedade das Nações cujo cargo de alto comissário foi designado ao norueguês Fridtjof Nansen. Ele era uma espécie de cartão de identidade fornecido a apátridas que, com ele, tinham a possibilidade de adentrarem legalmente nos países (Betts; Loescher, 2011, p. 7-8).

Enquanto foi desenvolvida uma estrutura incipiente para os refugiados no período entre guerras, tal regime teve seus desenhos solidamente traçados no fim da II Guerra Mundial, quando houve um fluxo de mais de 1 milhão de refugiados. Em 1946, um ano após a criação da Organização das Nações Unidas (ONU), começaram as atividades para o estabelecimento da Organização Internacional para os Refugiados (OIR), uma vez que os Estados viram a necessidade de lidar com o grande fluxo de refugiados presentes na Europa. Com isso, a OIR entrou em funcionamento no ano de 1948. Essa organização, porém, não teve muito sucesso e foi inábil em lidar com os conflitos políticos da época, de modo que outro sistema precisasse ser pensado (CUNHA; ALMEIDA, 2008, p. 435-437).

Além da OIR, foi criada também no âmbito das Nações Unidas a Agência de Assistência aos Refugiados Palestinos no Oriente Próximo (UNRWA - United 
Nations Relief and Works Agency for Palestine Refugees in the Near East, em inglês). Houve necessidade alarmante de acolhida humanitária aos palestinos que se viram obrigados a fugir do conflito árabe-israelense de 1948. Dessa forma, a agência iniciou suas atividades em 1950 para prover serviços de assistência emergencial aos palestinos. Diante da continuidade do "problema" dos refugiados palestinos, o mandato da agência tem sido renovado repetidamente (UNRWA, s.d.).

Em resposta ao fluxo de deslocamento forçado na Europa, os Estados se organizaram para formar dois documentos que institucionalizaram formalmente uma cooperação internacional em favor dos refugiados: o Estatuto de criação do ACNUR de 1950 e a Convenção de 1951. A agência iniciou suas atividades no dia $1^{\circ}$ de janeiro de 1951. $\mathrm{Na}$ época de sua criação, o mandato previsto para o ACNUR tinha duração de três anos e escopo limitado à Europa. No entanto, não demorou para se entender que o ACNUR não poderia acabar em três anos, uma vez que os fluxos de refugiados só iam aumentando ao longo do tempo. Os refugiados vinham de todo lugar: Europa, África, América Latina e Ásia. Paralelamente ao seu crescimento de atuação em termos de regiões e quantidade, o ACNUR ampliou seu mandato para atender grupos vulneráveis como apátridas e deslocados internados, existentes em abundância no início do século XXI (ACNUR, 2013b).

De acordo com seu estatuto, o ACNUR é previsto para ter caráter meramente humanitário e social e não apresenta viés político. Seu objetivo principal, então, é a proteção e promoção dos direitos dos refugiados. No entanto, a agência foi estabelecida num momento de grande tensão política do início da Guerra Fria e a maior parte de seus recursos advêm de doações voluntárias dos Estados-membros da Convenção de Genebra e do Estatuto do ACNUR. Assim, relações e interesses políticos dos Estados encontramse invariavelmente na proteção do seu mandato, que é exercido em forma de assistência jurídica e social por meio de ações que vislumbram estratégias de prevenção e reparação. Enquanto o refugiado não for repatriado ou reconhecido como refugiado por outro Estado, a proteção do ACNUR, ainda que restringida, é indispensável, uma vez que seus direitos ficam na iminência de serem violados (CUNHA; ALMEIDA, 2008, p. 428-29).

Dessa forma, o ACNUR é atualmente a entidade internacional incumbida de cuidar dos refugiados no mundo. Estima-se que cerca de 33.9 milhões de pessoas estejam sendo atendidas por essa agência no momento. Deste total, 14.7 milhões são deslocados internos; 10.5 milhões refugiados; 3.1 . milhões repatriados; 3.5. milhões apátridas; mais 
de 837 mil solicitantes de asilo; e 1.3 de outros casos. Essa última categoria de deslocados assistidos muito provavelmente insere-se no termo que o ACNUR tem utilizado frequentemente "refugee like situation" para se referir a pessoas que se encontram em situação similar a de refúgio e que igualmente apresentam demandas equivalentes, mas que não são consideradas "refugiadas" de acordo com a definição tradicional da Convenção de 1951 (ACNUR, 2013a).

Por fim, o ACNUR é a única organização global com mandato específico de assegurar a proteção e assistência aos refugiados (Betts et al., 2008, 104-105). A despeito disso, todo e qualquer trabalho desempenhado pelo ACNUR seria inviável sem o auxílio de instituições parceiras. São diversos atores internacionais que viabilizam a atuação do ACNUR: agências das Nações Unidas; organizações não-governamentais de cunho local, regional, nacional e internacional; agências dos governos nacionais; e diversos outros. Desde o princípio, o ACNUR conta com a assistência desses atores para desenvolver suas atividades. O Comitê Internacional da Cruz Vermelha (CICV) e os Médicins Sans Frontières (MSF) são exemplos de alguns parceiros tradicionais no auxílio da atuação do ACNUR em áreas próximas a regiões de conflito. Já no Brasil, o ACNUR tem seu escritório sede em Brasília e, muito recentemente, conta com um escritório na cidade de São Paulo também, além de contar com forte apoio de outras instituições nos demais estados, como é o caso das Cáritas Arquidiocesanas no Rio de Janeiro e em São Paulo.

De modo geral, entretanto, deve-se constatar que, a despeito de todo empenho, o ACNUR não possui estrutura para suprir as necessidades diversas de todos os refugiados ao redor do mundo. Na realidade, esse não seria o propósito genuíno da agência. Ocorre, porém, que boa parte das iniciativas em prol dos refugiados ficam centralizadas no ACNUR, enquanto que os Estados têm tido poucas atitudes progressistas e exemplares a esse respeito.

\section{CONSIDERAÇÕES FINAIS}

Toda grande mudança começa com uma crítica consistente. É com esse olhar que este artigo buscou contribuir para ferramentas e reflexões no aprimoramento da garantia de direitos de pessoas como os refugiados por meio de uma crítica ao sistema de assistência corrente cujas implicações humanitárias para os refugiados tem sido muito negativas, sobretudo no que diz respeito ao insucesso de garantia dos direitos dos mesmos.

Este estudo buscou delinear a inserção dos refugiados no sistema internacional, analisando criticamente as perspectivas de proteção dos mesmos. Dessa forma, demonstrou que $\mathrm{o}$ aparato protetivo disponível, de acordo com o 
sistema internacional de proteção dos direitos humanos, não abrange satisfatoriamente na prática todos os humanos. Algumas pessoas não estão inseridas regularmente na organização do sistema internacional, como os refugiados, por exemplo. De modo geral, refugiados cruzam fronteiras internacionais com o objetivo de fugir de abusos de direito e conflito. Os motivos que provocam refúgio são diversos, porém, invariavelmente, eles são relacionados a conflitos de violência generalizada, violação massiva de direitos humanos e desigualdade na economia política internacional.

Por essa razão, os refugiados são a prima facie de violação de direitos humanos, de maneira que eles deparem-se numa situação de ausência de garantia de direitos. Com isso, inúmeras críticas emergem quanto a relação estreita entre garantia de direitos humanos e os Estados. Responder, então, às demandas dos refugiados implica um desafio para a ordem mundial. Pois, uma vez que o indivíduo não pode mais contar com o aparato estatal para defender seus direitos, ele se encontra em vulnerabilidade.

A união de perspectivas de Direito, Relações Internacionais e Filosofia Política permitiu uma compreensão mais ampla e com maior potencial crítico para refletir acerca da proteção e da promoção de direitos em prol dos refugiados, tornando possível constatar que os refugiados encontram-se em limbo de direitos devido ao fato de fugirem à regra do sistema internacional fundado em Estados-Nação. Documentos regionais e internacionais, bem como o ACNUR são tentativas de minimizar a perda da dignidade humana dos refugiados sem, contudo, suprir adequadamente sua demanda eminente.

Portanto, a complexidade em consolidar um mecanismo para atender aos refugiados evidencia fragilidade, falhas e lacunas do sistema internacional de proteção aos Direitos Humanos. Isso porque a centralização nos Estados do regime internacional de proteção pressupõe um viés assistencialista frágil, que não tem se mostrado garantidor de direitos. No mesmo sentido, o fato do ACNUR encontrar limitações em sua atuação devido aos interesses dos Estados implica um drástico dano ao propósito do seu papel ser genuinamente humanitário. Assim, mesmo os mecanismos de proteção que não são propriamente os Estados, como é o caso do ACNUR que tem mandato exclusivo de proteger as pessoas que sofreram deslocamento forçado, acabam dependendo dos atores estatais, provocando uma circularidade na relação entre proteção advinda do Estado e acolhimento humanitário. Dessa forma, direta ou indiretamente, a ajuda humanitária aos refugiados desafia a configuração vigente do sistema político internacional e, por conseguinte, do sistema internacional de proteção aos Direitos Humanos. 


\section{REFERÊNCIAS}

1951 CONVENTION RELATING TO THE STATUS OF REFUGEES AND ITS 1967 PROTOCOL, THE. Genebra, 2011. Disponível em: $<$ http://www.unhcr.org/4ec262df9. html >. Acesso em: 20 maio 2013.

AGAMBEN, Giorgio. Means without end: notes on politics. Minneapolis: University of Minnesota, 2000. $158 \mathrm{p}$.

. Homo Sacer: o poder soberano e a vida nua I. Tradução de Henrique Burigo. 2 ed. Belo Horizonte: Editora UFMG, 2010. 197 p.

AGIER, Michel. Managing the undesirables: Refugee camps and humanitarian government. Flammarion: Polity, 2011. 276 p.

ALTO COMISSARIADO DAS NAÇÕES UNIDAS PARA REFUGIADOS (ACNUR). The state of the world's refugees 2000: fifty years of humanitarian action. 2000. Disponível em: <http://www.unher. org $/ 4 a 4 c 754 a 9 . h t m l>$. Acesso em: 20 abr. 2012.

. The civilian character of asylum: separating armed elements from refugees. In: Global consultations on international protection. 2001. Disponível em: $<$ http://www. unhcr.org/refworld/pdfid/3bfa82d65. pdf $>$. Acesso em: 14 jun. 2012. . Contributions to UNHCR for Budget Year 2012. 2012. Dispo- nível em: <http://www.unhcr.org/ 4df1d0449.html>. Acesso em: 30 maio 2013.

. History of UNHCR. 2013a. Disponível em: $<$ http://www.unhcr.org/ pages $/ 49 \mathrm{c} 3646 \mathrm{cbc} \cdot \mathrm{html}>$. Acesso em: 21 maio 2013.

. O que é a Convenção de 1951? 2013b. Disponível em: <http:// www.acnur.org/t3/portugues/informacao-geral/o-que-e-a-convencaode-1951/>. Acesso em: 21 maio 2013.

ARENDT, Hannah. O declínio do Estado-nação e o fim dos direitos do homem. In: . Origens do Totalitarismo: anti-semitismo, imperialismo, totalitarismo. 9 ed. São Paulo: Companhia das Letras, 1989. p. 300-336.

BARNETT, Michael. Humanitarianism, Paternalism, and the UNHCR. In: BETTS, Alexander; LOESCHER, Gil (Ed.). Refugees in International Relations. Nova Iorque: Oxford University, 2011. p. 1-28

BARNETT, Michael; WEISS, Thomas $\mathrm{G}$ (Ed.). Humanitarianism in question: politics, power and ethics. Ithaca: Cornell University, 2008. 308 p. BETTS, Alexander; LOESCHER, Gil. Refugees in International Relations. In: . Refugees in International Relations. Nova Iorque: Oxford University, 2011. p. 1-28. 
BETTS, Alexander; LOESCHER, Gil; MILNER, James. UNHCR: the politics and practice of refugee protection. 2 ed. Nova Iorque: Routledge, 2008. p. 7-132.

CRISP, Jeff. Mind the gap!: UNHCR, humanitarian assistance and the development process. New Issues in Refugee Research, n. 43. 2001. Disponível em: $<$ http://www.unhcr. org/3b309dd07.html $>$. Acesso em: 25 maio 2013.

CUNHA, Guiherme; ALMEIDA, Guilherme. Introdução à Parte II: Direito Internacional dos Refugiados. In: PIOVESAN, Flávia. Código de Direito Internacional dos Direitos Humanos. São Paulo: DPJ Editora, 2008. p. 423-442.

DECLARAÇÃO DE CARTAGENA SOBRE OS REFUGIADOS, DE 1984. In: Coletânea de Instrumentos de Proteção Internacional dos Refugiados. Brasília: Servidéias Comunicações, 2010. p. 73-79.

DECLARAÇÃO DE SÃO JOSÉ SOBRE REFUGIADOS E PESSOAS DESLOCADAS, DE 1994. In: Coletânea de Instrumentos de Proteção Internacional dos Refugiados. Brasília: Servidéias Comunicações, 2010. p. 80-88.

DECLARAÇÃO E PLANO DE AÇÃO DO MÉXICO(PAM) PARA FORTALECER A PROTEÇÃO INTERNACIONAL DOS REFUGIADOS NAAMÉRICA LATINA, DE 2004.
In: Coletânea de Instrumentos de Proteção Internacional dos Refugiados. Brasília: Servidéias Comunicações, 2010. p. 89-107.

DUARTE, André. Sobre a biopolítica: de Foucault ao século XXI. In: Estética da Biopolítica: ensaios críticos. 2013. Disponível em: <http:// www.revistacinetica.com.br/cep/ andre_duarte.htm>. Acesso em: 25 abr. 2013.

FOLEY, Conor. Human Rights and Humanitarians. In: . The Thin Blue Line. Nova Iorque: Verso, 2010. p. 21-43.

HADDAD, Emma. The refugee in international society: between sovereigns. Cambridge: Cambridge University, 2008. 250 p.

HYNDMAN, Jennifer. Managing displacement: refugees and the politics of humanitarianism. Minneapolis: University of Minnesota, 2000. $253 \mathrm{p}$.

KALDOR, Mary. New and old wars: organized violence in a global era. 1999. Stanford: Polity Press, 1999.

LOESCHER, Gil. Beyond Charity: international cooperation and the global refugee crisis. New York: Oxford University Press, 1993. p. 3-31. MINEAR, Larry; WEISS, Thomas G. Humanitarian Politics. Headline Series. n. 304. Nova Iorque: Foreign Policy Association, 1995. $72 \mathrm{p}$. NOBEL FOUNDATION. The Nansen International Office for Refugees: 
History of Organization. 2013. Disponível em: <www.nobelprize.org/ nobel_prizes/peace/laureates/1938/ nansen-history.html>. Acesso em: 23 maio 2013.

O PROJETO ESFERA. Carta Humanitária e Normas Mínimas de Resposta Humanitária em Situação de Desastre. [S.1.]: Oxfam, 2000. p.171-214.

OSIANDER, Andreas. Sovereignty, International Relations and the Westphalian Myth. International Organization, n. 55, 2001, p. 251-287. Disponível em: <http://www.jstor.org/discover/10.2307/3078632?uid=2\&ui$\mathrm{d}=4 \&$ sid $=21102351421121>$. Acesso em: 20 jun. 2013.

ÖZERDEM, Alpaslan; RUFINI, Gianni. Humanitarianism and the Principles of Humanitarian Action in Post-Cold War Context. 2005. Disponível em: $<$ http://www.terzomondo.org/writings/writings/Gianni_Rufini_2005 York_Humanitarianism_and_Principles.pdf $>$. Acesso em: 20 abr. 2013. RIEFF, David. Bed for the night: humanitarianism in crisis. Nova Iorque: Simon and Schuster, 2002. p. 1-122;155-196.

TERRY, Fiona. Condemned to repeat? the paradox of humanitarian action. Ithaca: Cornell University, 2002. p. 17-54; 155-215; 247-276.

TRINDADE, Antônio Augusto Cançado. Human Development and Human Rights in the International Agenda of the XXIst Century. In: Human Development and Human Rights Forum. San José da Costa Rica: United Nations Development Program, 2001.

. Dilemas e desafios da Proteção Internacional dos Direitos Humanos no limiar do século XXI. Revista Brasileira de Politica Internacional, Brasília, v. 40, n. 1, jun. 1997. Disponível em: <http://www.scielo.br/scielo. php?script=sci_arttext\&pid=S003473291997000100007\&lng=pt\&nr $\mathrm{m}=$ iso $>$. Acesso em: 25 abr. 2013.

UNITED NATIONS EDUCATIONAL, SCIENTIFIC AND CULTURAL ORGANIZATION (UNESCO). Social and Human Sciences: nation-state. 2012. Disponível em: $<$ http://www.unesco.org/new/en/ social-and-human-sciences/themes/ international-migration/glossary/ nation-state/>. Acesso em: 29 maio 2013.

UNITED NATIONS HIGH COMMISSIONER FOR REFUGEES. World Refugee Day: Global forced displacement tops 50 million for first time in post-World War II era. 20 jun. 2014. Disponível em: $<$ http:// www.unhcr.org/53a155bc6.html >. Acesso em: 23 jun. 2014.

UNITED NATIONS RELIEF AND WORKS AGENCY FOR PALESTINE REFUGEES (UNRWA). Who we are, s.d. Disponível em: $<\mathrm{http}: / /$ 
www.unrwa.org/who-we-are>.

Acesso em: 20 jul. 2014.

WORLD BANK, THE. Forced Dis-

placement, 2013. Disponível em: <http://web.worldbank.org/ WBSITE/EXTERNAL/TOPICS/ EXTSOCIALDEVELOPMENT/0, contentMDK:22463823 pagePK:148956 piPK:216618 the-
SitePK:244363,00.html>. Acesso em: 20 jun. 2013.

WORLD HEALTH ORGANIZATION (WHO). Environmental health in emergencies: complex emergencies. WHO. Disponível em: $<$ http:// www.who.int/environmental_health_emergencies/complex_emergencies/en/>. Acesso em: 6 maio 2013. 